\title{
Case Report \\ Total Colonic Expulsion with Part of Small Bowel per Vaginum due to Low-Flow Phenomenon and NOMI: A Case Report
}

\author{
Suha Deen ${ }^{1}$ and Martin Powell ${ }^{2}$ \\ ${ }^{1}$ Department of Histopathology, Level A, West Block, Queen's Medical Centre Campus, Nottingham University Hospitals, \\ Derby Road, Nottingham NG7 2UH, UK \\ ${ }^{2}$ Department of Obstetrics and Gynaecology, Queen's Medical Centre, Nottingham, UK
}

Correspondence should be addressed to Suha Deen, sdeen@doctors.org.uk

Received 14 January 2011; Accepted 7 February 2011

Academic Editor: Lars Aabakken

Copyright (C) 2011 S. Deen and M. Powell. This is an open access article distributed under the Creative Commons Attribution License, which permits unrestricted use, distribution, and reproduction in any medium, provided the original work is properly cited.

Introduction. Intestinal ischaemia is a devastating disease process that could lead to bowel gangrene and death if either not diagnosed early or left untreated; death is usually caused by irreversible shock, intestinal necrosis, or septicaemia. It is usually seen in elderly patients with atherosclerotic disease. The course of bowel ischaemia may affect variable lengths of the intestine and it is not unusual for the condition to be followed by uneventful recovery. Case presentation. We are reporting an unusually rare case where an elderly patient passed an extraordinarily long segment of bowel, including rectum, the whole of the large bowel, and part of the small bowel, through anus following an episode of nonobstructive mesenteric ischaemia (NOMI) complicating myocardial infarction. To our knowledge, there are only eight cases reported in the literature where the condition was diagnosed upon the passage of short segments of the large bowel particularly of the rectosigmoid segment through the anus. Conclusion. Physician should keep a high level of suspicion in order to prevent it or at least recognise it early on and offer adequate management and hence reducing morbidity and mortality.

\section{Case Report}

An elderly female patient was treated for a fractured right neck of femur. Her Auston-Moore right hip replacement was uneventful. One week later, she became unwell with increasing shortness of breath and abdominal distension. A diagnosis of posterior myocardial infarction and pseudoobstruction of the bowel was made and treated accordingly. Her general condition was fluctuating with recurrent diarrhoea, swinging temperature, and persistent confusion. Three weeks following her admission and while on the rehabilitation ward, a foul vaginal discharge was noted and a cordlike piece of tissue was seen protruding through the vagina. Later on, a piece of bowel was passed out through the vagina and placed in formalin pot following resection. The patient had had a vaginal shelf pessary fitted sometime ago. A diagnosis of vaginoenteric fistula was strongly suspected. The patient was too unwell for imaging studies such as MRI or
CT scan. During this period and despite intensive treatment of her septicaemia, she continued to deteriorate and passed away six weeks following the hip replacement. A postmortem examination was refused by the relatives.

\section{Histopathological Examination}

2.1. Macroscopy. The specimen was a long cordlike greenish yellow tissue measuring $1350 \times 20 \mathrm{~mm}$ maximum without any identifiable viable tissue (Figure 1(a)).

2.2. Microscopic Examination. Microscopic examination of sections of the tissue revealed predominantly large and partly small bowel tissue with different and variable thickness ranging from mucosa and submucosa up to and including the inner and outer layers of the muscularis propria (Figures $1(\mathrm{~b}), 1(\mathrm{c})$, and $1(\mathrm{~d}))$. 


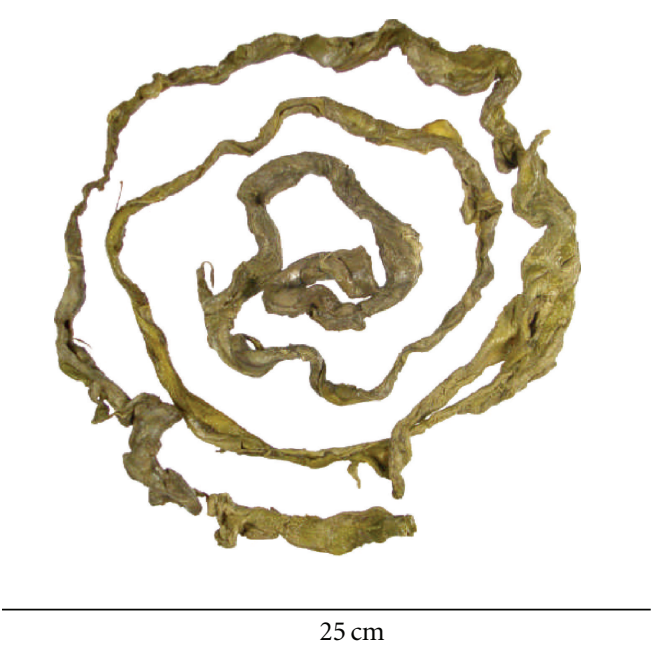

(a)

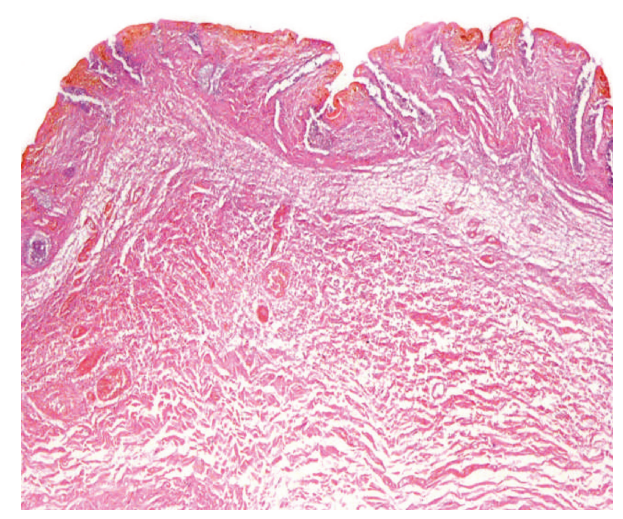

(c)

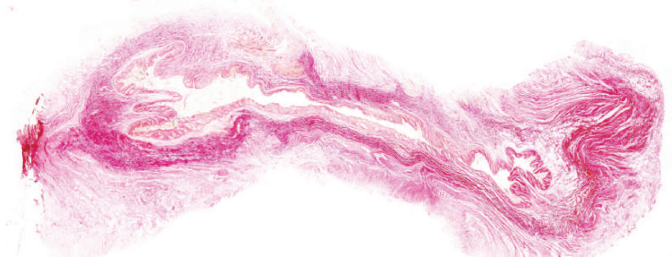

(b)

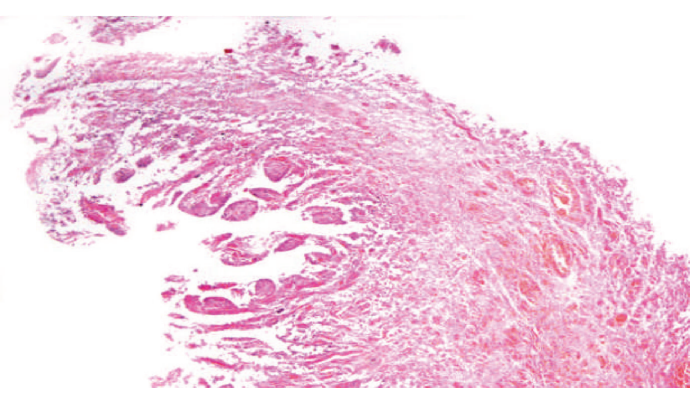

(d)

Figure 1: (a) Macroscopic view of the expelled loop of intestine as received showing pronounced degenerative and ischaemic changes. (b) Low power view of a section of the infarcted large bowel; EVG special stain. (c) High power view of (b) showing oedematous and necrotic tissue. (d) One end of the specimen showing small bowel mucosa.

\section{Discussion}

Spontaneous passage of a large bowel cast caused by acute ischaemic injury is an extraordinary complication of mesenteric ischaemia. A literature search through PubMed using the keywords colon, rectum, ischaemia, infarction, sloughed, passed, per vaginam, and per rectum revealed 8 cases in which a short segment ranging between $25 \mathrm{~cm}$ of recto-sigmoid and $96 \mathrm{~cm}^{3}$ of descending colon down to the upper rectum was passed per anum [1-6]. However, in our interesting case not only was there a spontaneous expulsion of the whole of the colon and part of the small bowel to a length of $135 \mathrm{~cm}$ but also the bowel cast expelled per vaginum.

Of the eight reported cases, ischaemic complication occurred following abdominal aortic aneurysm repair in five cases; all patients survived this complication except for one case of a 67-year-old male who passed a full thickness cast of sigmoid colon $25 \mathrm{~cm}$ long following abdominal aortic aneurysm repair; the latter case was reported by Sado et al. in J Jpn Soc Colorectal Dis (in Japanese) [1]. Whilst in seven of these cases, as well as our case, infarcted muscularis propria was also found in addition to necrotic mucosa and submucosa [1-6].

The mortality following bowel ischaemia remains high although it has dropped from $85 \%$ to $60 \%$ over the last 30 years due to advances in early diagnosis and management. However, the latter, as expected, has led to increase in the incidence of this entity [7].

The aetiology of bowel ischaemia is obviously secondary to a compromise in blood flow to the bowel. This may be attributed to a predisposing obstructive factor causing segmental ischaemia or has a non-obstructive aetiology. The latter is usually secondary to cardiovascular events and could affect the major supply of the celiac axis and superior and inferior mesenteric arteries. The likely causes of nonobstructive intestinal ischaemia include

(1) dissecting aortic aneurysm with secondary compression of both main mesenteric arteries, 
(2) vasospasm of both mesenteric arteries secondary to medications for example, digoxin, ergot, and cocain intoxication [7],

(3) low-flow phenomenon precipitated by hypovolaemia, severe hypotension, or shock [8],

(4) haematological clotting causes predisposing to excessive clotting mechanism.

In our case report, there was no history of clotting disorder, vasoactive medication, or aortic dissection. Other than the unlikely event of two simultaneous and separate thrombi of the superior and inferior mesenteric arteries, it seems that low-flow phenomenon complicating myocardial infarction and progressing to extensive intestinal tissue necrosis and pronounced sloughing of this tremendous length of bowel is the most likely pathological explanation to what had happened to our patient. Mortality is usually very high if this unexpected extensive and severe intestinal infarction presented together with the recent myocardial infarction.

NOMI accounts for $15-20 \%$ of acute cases of intestinal ischaemia and is mostly seen in patients who are already critically ill [7]. Systemic hypotension is often followed by splanchnic and peripheral vasoconstriction. This physiological response will predispose to NOMI particularly in the elderly population whose vascular bed is already compromised by systemic atherosclerosis [9].

This lady had had a vaginal ring pessary fitted for uterine prolapse. The clinical history is clear that there was a significant foul vaginal discharge and a cordlike pieces of tissue protruding from the vagina. It is clinically recognised that neglected vaginal pessary in certain circumstances might erode through vaginal wall predisposing to a fistula [10].

\section{Conclusion}

This is a very unusual case of extensive non-obstructive intestinal ischaemia affecting the area supplied by the superior and inferior mesenteric arteries, that is, including rectum, the whole of the large bowel, and part of the small bowel. Ischaemic change was most likely secondary to a low flow phenomenon precipitated by prior myocardial infarction. Physician should keep a high level of suspicion in order to prevent it or at least recognise it early on and offer adequate management and hence reducing morbidity and mortality.

\section{Conflict of Interests}

The authors declare no conflict of interests.

\section{References}

[1] G. J. Ardigo, G. F. Longstreth, L. A. Weston, and F. D. Walker, "Passage of a large bowel cast caused by acute ischemia: report of two cases," Diseases of the Colon and Rectum, vol. 41, no. 6, pp. 793-796, 1998.

[2] M. J. Speakman and A. R. Turnbull, "Passage of a colon 'cast' following resection of an abdominal aortic aneurysm," British Journal of Surgery, vol. 71, no. 12, p. 935, 1984.
[3] P. J. Gregory and G. Barrett, "Spontaneous passage of a colon 'cast' in a patient with ischaemic colitis," British Journal of Surgery, vol. 74, no. 5, p. 436, 1987.

[4] R. K. Phillips and N. C. Armitage, "Colon "cast" in a patient with ischaemic colitis," British Journal of Surgery, vol. 74, no. 8, pp. 759-760, 1987.

[5] Y. Sakanoue, M. Kusunoki, and Y. Shoji, "Passage of a colon 'cast' after anoabdominal rectal resection: report of a case," Diseases of the Colon and Rectum, vol. 33, no. 12, pp. 10441046, 1990.

[6] H. Yoshiji, D. Nakae, R. Sugiya et al., "Spontaneous passage of a colon cast in the absence of abdominal aneurysm," Journal of Gastroenterology, vol. 29, no. 1, pp. 80-83, 1994.

[7] S. Shetty, G. Morris-Stiff, and M. H. Lewis, "Intestinal ischaemia," Hospital Medicine, vol. 63, no. 6, pp. 354-360, 2002.

[8] D. C. Vicente and A. Kazmers, "Acute mesenteric ischemia," Current Opinion in Cardiology, vol. 14, no. 5, pp. 453-458, 1999.

[9] G. Lock, "Acute intestinal ischaemia," Best Practice and Research Clinical Gastroenterology, vol. 15, no. 1, pp. 83-98, 2001.

[10] I. Goldstein, G. J. Wise, and M. L. Tancer, "A vesicovaginal fistula and intravesical foreign body. A rare case of the neglected pessary," American Journal of Obstetrics and Gynecology, vol. 163, no. 2, pp. 589-591, 1990. 


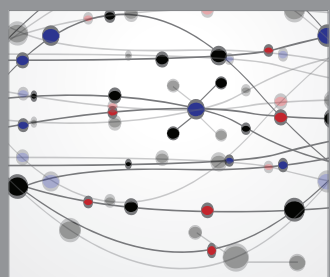

The Scientific World Journal
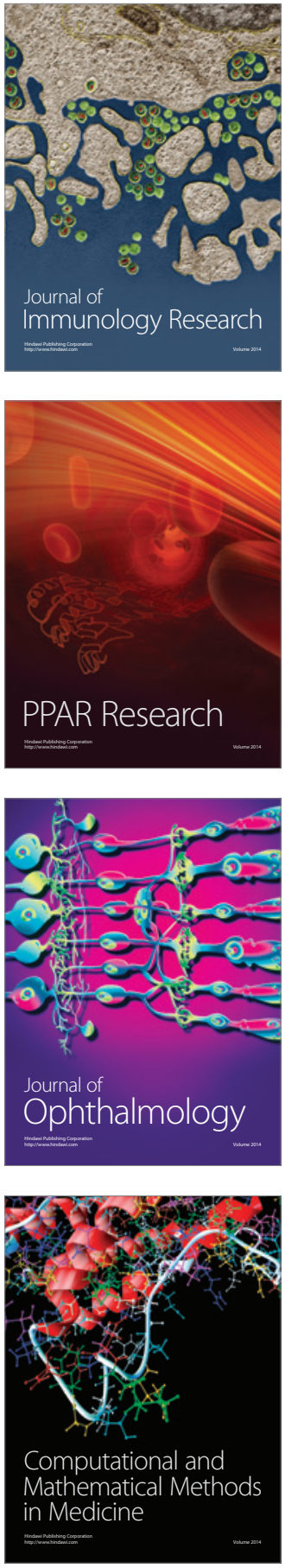

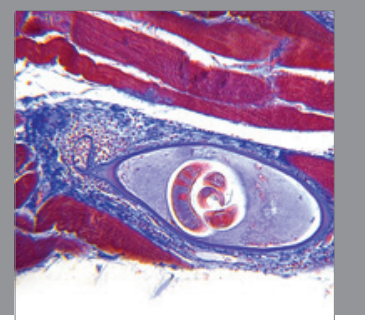

Gastroenterology

Research and Practice
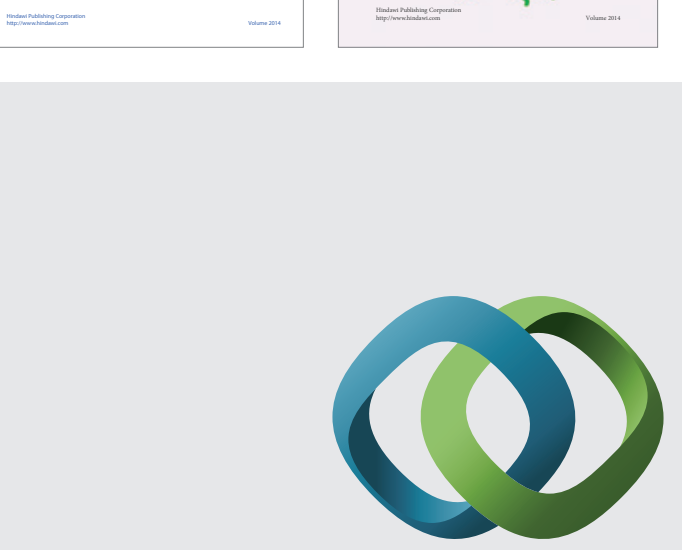

\section{Hindawi}

Submit your manuscripts at

http://www.hindawi.com
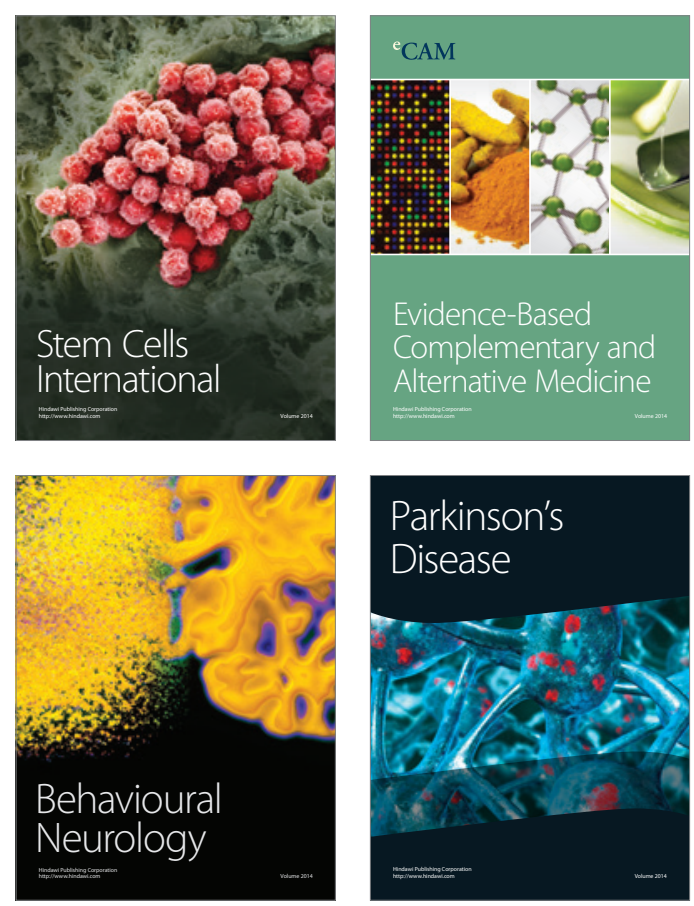

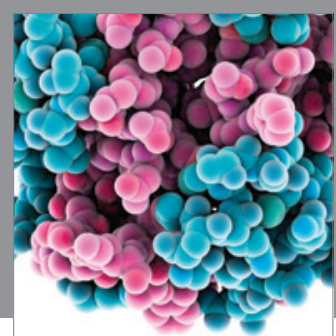

Journal of
Diabetes Research

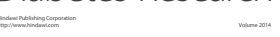

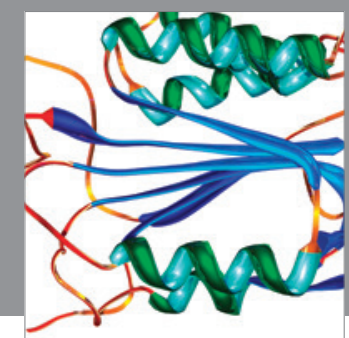

Disease Markers
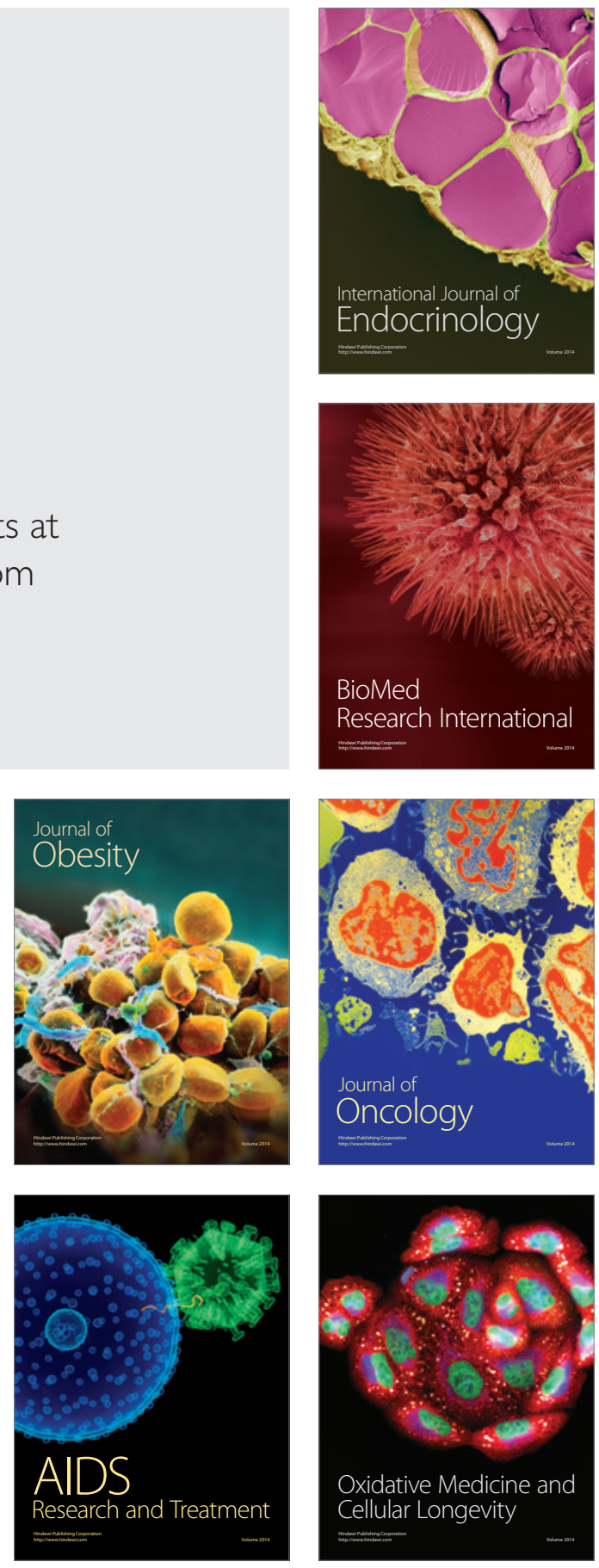